\title{
AUMC Infinity Observed Normalized by
} Surface Area

National Cancer Institute

\section{Source}

National Cancer Institute. AUMC Infinity Observed Normalized by Surface Area. NCI

Thesaurus. Code C92332.

The area under the first moment curve (AUMC) extrapolated to infinity, based on the last observed concentration divided by the surface area. 